\title{
RECURSOS DIGITALES AUTÓNOMOS MEDIANTE REALIDAD AUMENTADA
}

\author{
(AUTONOMOUS DIGITAL RESOURCES THROUGH AUGMENTED REALITY)
}

Joaquín Cubillo Arribas

Sergio Martín Gutiérrez

Manuel Castro Gil

Antonio Colmenar Santos

Universidad Nacional de Educación a Distancia (UNED), España

\section{RESUMEN}

Aún existen en la actualidad limitaciones a la hora de enseñar conceptos que requieren la manipulación o visualización de objetos que no están al alcance de todos, bien por su naturaleza abstracta, científica o espacial. La realidad aumentada y los dispositivos móviles son herramientas disponibles hoy en día que permiten solventar estas carencias y ofrecen la posibilidad de interactuar con objetos virtuales en un espacio tridimensional. Para que estas tecnologías formen parte activa en el ámbito educativo es necesario proporcionar herramientas de autor que faciliten la creación de contenidos aumentados autónomos, que expliquen por sí mismos los conceptos que van a ser mostrados, que permitan añadir de una forma sencilla y transparente nuevos recursos virtuales y que puedan ser reutilizados. Este trabajo presenta un entorno de aprendizaje basado en la realidad aumentada que cumple estos objetivos.

Palabras clave: realidad aumentada, aprendizaje móvil, herramientas de autor, contextualización, preguntas con respuesta múltiple.

\begin{abstract}
Even today there are limitations to teaching concepts that require a specific level of manipulation or visualization of objects (the later of which are not always available). This is often because of the abstract, spatial or scientific nature of the object in question. Augmented reality and mobile devices are tools that are available today, which enable us to overcome these deficiencies. What's more, they provide us with the ability to interact with virtual objects in a three dimensional space. For these technologies to form an active part of the educational environment, it is necessary to provide authorship tools that facilitate the creation of autonomous augmented resources, and explain the concepts that are presented to the student. It will also help with uploading- in a simple and transparent manner- virtual resources that can be re-utilized.This paper presents an augmented reality learning environment which fulfils these objectives.
\end{abstract}


Keywords: augmented reality, mobile learning, authoring tools, contextualization, multiple choice questions.

A pesar de que los libros y apuntes constituyen el soporte básico de la enseñanza, actualmente se están empleando nuevas herramientas para facilitar la docencia de los profesores y el aprendizaje de los estudiantes. Ordenadores personales, smartphones y tablets forman parte del entorno educativo de los alumnos, y el contenido virtual al que se accede con ellos constituye una red de datos disponible al alcance de la mayoría de todos ellos.

Las tecnologías actuales como la Web 2.o, los dispositivos móviles, los entornos virtuales o la realidad aumentada (RA), tienen el potencial para descubrir y proporcionar nueva información en cualquier ámbito (Carmigniani et al., 2010), distintos autores Facer et al. (2004); Williams et al., (2005) han investigado las ventajas del empleo de estas tecnologías en la transmisión y creación de conocimiento para el aprendizaje, ya que facilitan la adaptación y contextualización de los contenidos, lo que se ha denominado "aprendiendo a aprender con la tecnología" (Miglino \& Walker, 2010; Roblyer et al., 2006).

Sin embargo, y a pesar de emplearse estos dispositivos cada vez con más frecuencia, uno de los problemas que conllevan es la desconfianza que suscitan en los profesores (Van't Hooft \& Swan, 2007), puesto que en la mayor parte de los casos no se puede controlar lo que los alumnos están realizando con ellos, es decir, si verdaderamente están empleando los recursos para el aprendizaje o están realizando otras tareas (Dieterle \& Dede, 2006).

En esta revolución de la información los estudiantes han dejado de ser meros consumidores de datos y hechos para pasar a ser creadores activos de recursos y de conocimientos (Cameron \& Tanti, 2011); ahora cualquier estudiante puede crear un video o una presentación sobre cualquier tema y colgarlo en la red de forma que esté disponible para todo el mundo.

Holzinger, Nischelwitzer y Meisenberger (2007) consideraron que los problemas sobre las limitaciones del espacio y del tiempo en el aprendizaje no son resueltas por los métodos tradicionales de e-learning, por lo que el uso de nuevas tecnologías como los dispositivos móviles proporciona una deslocalización y una ubicuidad que se transforma en independencia con respecto al tiempo y el espacio en comparación con otras tecnologías que emplean el ordenador estándar (Virvou \& Alepis, 2005). 
Con toda esta tecnología al alcance de profesores y estudiantes y con toda la información disponible en la red se podría pensar que el aprendizaje y el estudio con estos materiales resulta una tarea simple; sin embargo, no todos los recursos son adecuados para todos los estudiantes, cada alumno tiene un ritmo de aprendizaje y por lo tanto debería tener un entorno personal de aprendizaje. Siguiendo en esta línea, la combinación de los dispositivos móviles con nuevas tecnologías como la RA pueden conllevar una micro-revolución en las técnicas de enseñanza y aprendizaje dada la gran difusión de estos dispositivos y el auge que está teniendo la RA (Ally, 2009; Doswell et al., 2006; Martín et al., Jan 2009; Papagiannakis et al., 2008; Rohaya et al., 2012; Santos \& Ali, 2011).

En este artículo se considera, en primer lugar, la RA como herramienta al servicio de la educación, del aprendizaje y de la orientación didáctica tal y como se presentará en la experiencia realizada con distintos alumnos. En segundo lugar, se define la RA como una tecnología específica con unas características propias en la que la mera visualización de los recursos virtuales deja incompleta una experiencia de aprendizaje que es necesario contextualizar y apoyar de forma directa o indirecta por el profesor para obtener una experiencia educativa de calidad.

\section{La Realidad Aumentada}

A pesar de que el concepto de RA se remonta a la década de 1960, el primer sistema formal de RA no se desarrolló hasta los años 90 por la compañía Boeing. A partir de entonces, se han ido llevando a cabo distintas conferencias sobre el tema incluyendo simposios internacionales sobre la RA o sobre los mundos virtuales, y los investigadores se han visto atraídos por las posibilidades de esta tecnología (Feiner et al., 1993).

La definición más popular sobre RA es la dada por Milgram y Kishino (1994) quienes indican que: "entre un entorno real y un entorno virtual puro esta la llamada realidad mixta y esta se subdivide en 2, la realidad aumentada (más cercana a la realidad) y la virtualidad aumentada (más próxima a la virtualidad pura)" (Hsiao \& Rashvand, 2011).

Otra definición comúnmente aceptada es la aportada por Ronald Azuma (1997) que acota a la RA a la que cumple estos tres requisitos:

- Combinación de elementos virtuales y reales.

- Interactividad en tiempo real.

- Información almacenada en 3D. 
Por lo tanto la RA es un sistema interactivo que tiene como entrada la información del mundo real y superpone a la realidad nueva información digital en tiempo real, esta información virtual pueden ser imágenes, objetos 3D, textos, videos etc. Durante este proceso, la percepción y el conocimiento que el usuario tiene sobre el mundo real se ve enriquecido (Grifantini, 2009).

Nos hemos centrado en esta tecnología puesto que es considerada como una de las 10 tecnologías más importantes desde el 2008 tal y como refleja Gartner Research (2012) o los informes de Horizont Report (Johnson et al., 2009; Johnson et al., 2010; Johnson et al., 2011) en los cuales se manifiesta el interés que ha suscitado en los investigadores el potencial pedagógico de la RA.

Otra de las tecnologías que ha cambiado nuestras vidas es la tecnología móvil que está inmersa de una forma cada vez más consciente en la enseñanza. En este sentido la RA permite crear experiencias de aprendizaje centradas en el estudiante y proporcionar oportunidades para la colaboración entre ellos o directamente con el profesor (Billinghurst \& Kato, 2002; Kamarainen et al., 2013; Kaufmann \& Schmalstieg, 2003; Klopfer et al., 2005; Klopfer \& Squire, 2007; Pemberton \& Winter, Jun 2009; Szalavári et al., 1998).

\section{Realidad Aumentada en la Educación}

Centrándonos en el ámbito educativo, la RA puede proporcionar grandes oportunidades en distintas áreas como la ciencia o la ingeniería, puesto que estas disciplinas conllevan en su currículum un enfoque práctico en el aula (Andújar et al., 2011; Azuma et al., 2001).

Los métodos tradicionales de aprendizaje cuyos contenidos están relacionados con la espacialidad o la representación tridimensional, crean un filtro cognitivo debido a que los diagramas u objetos son representados en dos dimensiones, este filtro existe incluso cuando se trabaja con objetos $3 \mathrm{D}$ en una pantalla de ordenador debido a que la manipulación de los objetos en el espacio se realiza a través de clics del ratón sobre una superficie bidimensional (Shelton, 2002), este es el caso de otras disciplinas donde los conceptos resultan abstractos o confusos para los estudiantes, bien por su complejidad o bien porque no se pueden concretar en algo físico, algo que puedan manipular, la RA ofrece para todos ellos la posibilidad de representar e interactuar con objetos virtuales en un espacio tridimensional.

Estos sistemas de aprendizaje con RA son extremadamente eficaces para proporcionar información detallada a los usuarios que desarrollan varias tareas al 
mismo tiempo (Kalawsky et al., 2000) potenciando especialmente la adquisición de una variedad de habilidades tales como la capacidad espacial, habilidades prácticas, la comprensión conceptual, y la investigación (Chen \& Tsai, 2012). Los investigadores indican que el uso de entornos de RA durante las clases podría proporcionar una motivación extra para los estudiantes (Cuendet et al., 2013; Matt Dunleavy, 2012; Wojciechowski \& Cellary, 2013;), y lo que es más, podrían crear posibilidades de aprendizaje colaborativo alrededor de contenidos virtuales en entornos no tradicionales (Bujak et al., 2013).

Desde un punto de vista tecnológico la RA compensa algunas de las deficiencias presentes en la educación como son:

- Experimentos o prácticas que no pueden ser realizadas debido a los costes del equipamiento, a la relación entre el número de equipos disponibles y los alumnos matriculados.

- La disponibilidad de las instalaciones, ya sea por espacio y/o por tiempo.

- La realización de experimentos complejos y peligrosos que en muchas ocasiones no son realizados debido a que pueden provocar lesiones en caso de que ocurra algún fallo, con la RA se puede interactuar con modelos virtuales en tiempo real y ver los resultados obtenidos superpuestos en el mundo real.

- Permite la observación de experimentos o fenómenos que ocurren tras un largo periodo de tiempo (meses, años, décadas...etc.) en segundos como por ejemplo las leyes de Mendel, aunque también nos permite el caso contrario facilitando la observación de aquello que transcurre en un instante (Ying Li, 2010).

Aparecen por lo tanto nuevas líneas de investigación y nuevos proyectos para comprobar la efectividad y/o el potencial de la RA en entornos educativos. Algunos ejemplos de utilización de RA en educación son:

- Construct3D (Kaufmann, 2004) es un sistema de RA diseñado para el aprendizaje de las matemáticas y la geometría.

- Mixed Reality Lab de Singapur ha desarrollado varios sistemas de RA con fines educativos como son: sistema de RA para el aprendizaje del sistema solar, un sistema de RA para el aprendizaje de los mecanismos de germinación de las plantas, etc. 
- Billinghurst et al. (2001) presentó el libro mágico "The Magic Book", el cual tiene el aspecto de un libro normal, sin embargo sus páginas encierran diversos marcadores de forma que al ser reconocidos muestran una imagen o historia, de este modo este tipo de libros pueden emplearse para narrar historias o cuentos, etc.

- En un sistema de RA para el estudio del interior del cuerpo humano (Juan et al., 2008), se observó que el sistema de RA consta de una gran aceptación sin importar el medio empleado para la visualización ya que se hicieron pruebas tanto con un monitor como con un HMD (Dispositivo de visualización que va ajustado a la cabeza del usuario), y que el sistema facilita en gran medida el aprendizaje de los distintos órganos del cuerpo humano.

- RA para enseñar ciencia en la escuela primaria (Kerawalla et al., 2006).

- Enseñanza del sistema solar y la relación entre los planetas (Shelton \& Hedley, 2002).

- SMART: Un Sistema de Realidad Aumentada para enseñar a estudiantes de $2^{\circ}$ grado (Freitas \& Campos, 2008).

- Realidad Aumentada para enseñar matemáticas y geometría (Kaufmann \& Schmalstieg, 2003).

- El proyecto ARERE (Augmented Reality environment for remote education). ARERE (Ying Li, 2010) constituye un sistema interactivo y colaborativo basado en la realidad aumentada en un sistema de educación a distancia.

- Estudio de la colisión elástica con realidad aumentada para alumnos de ingeniería (Lin et al., 2013; Wu et al., 2013).

- Ingeniería mecánica en combinación con Web3D (Liarokapis et al., 2004).

- Enseñanza de cálculo en múltiples variables (Esteban et al., 2006).

- Enseñanza de ingeniería industrial y mercantil (Lang \& Wössner, 2004).

- Control de un laboratorio remoto mediante la realidad aumentada para enseñar electrónica en formación profesional (Cubillo et al., 2012). 
Como se puede observar la RA se puede aplicar de formas muy diversas en multitud de campos, tanto en la enseñanza presencial como en la enseñanza a distancia o el e-learning. En los distintos proyectos que se han realizado empleando estas herramientas se ha llegado a la conclusión de que las nuevas tecnologías despiertan el interés de sus participantes convirtiendo la materia a tratar en algo más que mera información retransmitida. Convertir el aprendizaje en un juego, en un reto, en una aventura y un descubrimiento permite adquirir destrezas, confianza, responsabilidad, comunicación y relación tanto de entre los alumnos como entre los alumnos y sus profesores.

En Klopfer et al., (2005) se plantean algunas de las ventajas de la RA en el aprendizaje colaborativo, donde indican que las simulaciones de RA pueden ser diseñadas no solo para apoyar el aprendizaje relacionado con los contenidos disciplinarios sino que proporciona otro tipo de destrezas como el pensamiento crítico en pleno siglo XXI, la colaboración, el intercambio de información, el análisis de sistemas complejos, etc.

No se trata de implantar esta tecnología de forma radical sino emplearla como complemento de las herramientas tradicionales, puesto que una de las posibilidades que ofrece es la de dotar a los libros o cualquier material impreso (apuntes, ejercicios, notas etc.) de contenido virtual (objetos $3 \mathrm{D}$, imágenes, videos etc.), dado que las nuevas generaciones digitales emplean la tecnología de una forma natural e innata, emplear nuevos mecanismos que susciten su interés y despierten su curiosidad se hace imprescindible.

Ahora bien, para poder trabajar con esta tecnología se debe disponer de las herramientas adecuadas, tanto para su uso como para su desarrollo. A pesar del auge que ha tomado en estos últimos años la RA, las herramientas de RA específicas de educación son limitadas y la mayoría de ellas centradas en un tema específico lo que las hace poco versátiles para su aplicación en una educación general. Por otro lado, las aplicaciones más generales no ofrecen ciertas características como la contextualización de los contenidos, o una descripción de los mismos por lo que cuando son empleadas por los estudiantes actúan como meros reproductores de RA, esto es, los alumnos únicamente se limitan a ver la representación del objeto virtual sin obtener información o contextualización (Bower \& Clark, 1969; Goodson et al., 2010; Luckin et al., 2001) sobre aquello que están viendo o con lo que están interactuando. Estas carencias ponen de manifiesto la necesidad de desarrollar herramientas de autoría que cuenten con características básicas propias de la educación como son la contextualización del aprendizaje (reconocido como un soporte que ayuda a dar sentido a la experiencia que se está llevando a cabo y que 
permite organizar el conocimiento incrementando la motivación (Dettori \& Paiva, 2009) la clasificación de los recursos o el seguimiento del aprendizaje, de hecho, el grupo de interés especial "Narrative and Learning Environments", analiza las ventajas de la incorporación de las narrativas en los nuevos entornos de aprendizaje (Dettori et al., 2006; Dettori \& Paiva, 2009) con resultados muy favorables.

Con todo ello se han desarrollado algunas herramientas de RA que cumplen estos requisitos (Lampe \& Hinske, 2007; MacIntyre et al., 2001), pero que sin embargo son aplicables únicamente a materias específicas como matemáticas, física y química y en su mayoría incorporan contenidos estáticos y predefinidos por sus desarrolladores no habiendo lugar para la creación o adición de nuevos contenidos, de este modo resulta imposible su uso en otras áreas distintas para las que fueron desarrolladas.

Otro punto a considerar es que no existe una biblioteca o fuente de recursos virtuales adaptados a la RA para que los profesores o alumnos los puedan emplear en cualquier momento. Esto es un problema puesto que la creación de contenidos en $3 \mathrm{D}$ adecuados, o incluso la búsqueda de los mismos no es una tarea trivial y estos recursos constituyen la parte fundamental de la tecnología RA. Las investigaciones recientes señalan que los profesores reconocen el potencial de la RA en la educación, sin embargo les gustaría controlar los recursos y adaptarlos a las necesidades de los estudiantes (Kerawalla et al., 2006).

Como resumen de las conclusiones obtenidas por diversos estudios como los indicados anteriormente podemos señalar que el empleo de la RA facilita, motiva y hace más agradable la explicación y asimilación de los contenidos tanto para los profesores como para los alumnos, estimula y motiva el aprendizaje cumpliendo de este modo con uno de los objetivos de la enseñanza que es provocar el interés que llevará a los alumnos a investigar, profundizar, analizar e invertir tiempo en aquello que les ha despertado dudas, interrogantes etc. En este sentido se confirman informes como por ejemplo (Hornecker \& Dunser, 2007); sin embargo, las carencias en las herramientas de autoría actuales abren el camino para la creación de nuevos entornos de RA que se puedan emplear para personalizar las experiencias de aprendizaje de cualquier estudiante de una forma autónoma.

\section{Herramientas de Autoría de Realidad Aumentada en la Educación}

La complejidad de la integración de la tecnología RA en la enseñanza representa un gran problema por diversos motivos. En primer lugar porque muchos profesores ni siquiera conocen la tecnología de la RA, esta puede resultar confusa o interpretarse 
como si fuese un mundo virtual; por otro lado, aquellos que la conocen no piensan en emplearla en las aulas ya que no saben exactamente en qué consiste esta tecnología; aquellos otros que la conocen y saben en qué consiste no la emplean puesto que el desarrollo de los contenidos virtuales (objetos 3D, videos etc.) es una tarea compleja y laboriosa; y por último, y los que menos son los profesores que sí la emplean en el aula y que han desarrollado experiencias educativas en esta línea.

En la Tabla 1 se muestra el resultado de una encuesta llevada a cabo entre 42 profesores de diferentes centros de enseñanza, escuelas, institutos y universidad pertenecientes a 11 ciudades distintas de España (12 profesores de escuelas de primaria, 12 profesores de secundaria, 17 profesores de centros de formación profesional y 1 profesor de universidad).

\begin{tabular}{|c|c|c|c|}
\hline Preguntas & \multicolumn{3}{|c|}{ Respuestas (\%) } \\
\hline $\begin{array}{l}\text { ¿Usa las nuevas tecnologías en } \\
\text { su labor docente. Dispositivos } \\
\text { móviles, pizarra digital, } \\
\text { simuladores, recursos multimedia } \\
\text { etc.? }\end{array}$ & $\begin{array}{l}\text { Sí, normalmente } \\
61.9\end{array}$ & $\begin{array}{l}\text { Sí, alguna vez: } \\
30.95\end{array}$ & No: 7.14 \\
\hline $\begin{array}{l}\text { ¿Emplea videos, imágenes u } \\
\text { objetos } 3 \mathrm{D} \text { en sus clases? }\end{array}$ & $\begin{array}{l}\text { Sí, normalmente } \\
47.62\end{array}$ & $\begin{array}{l}\text { Sí, alguna vez: } \\
38.10\end{array}$ & No: 11.9 \\
\hline $\begin{array}{l}\text { ¿Crea su propio contenido digital } \\
\text { (videos, objetos, presentaciones } \\
\text { etc.)? }\end{array}$ & $\begin{array}{l}\text { Sí, desarrollo mis } \\
\text { propios recursos } \\
\text { digitales: } 16.67\end{array}$ & $\begin{array}{l}\text { Sí, creo mis } \\
\text { recursos a partir } \\
\text { de otros. } 54.76\end{array}$ & No: 26.19 \\
\hline $\begin{array}{l}\text { ¿Tiene conocimientos de diseño } \\
\text { de objetos en 3D con software } \\
\text { como Maya, Blender, 3D Studio, } \\
\text { AutoCAD? }\end{array}$ & $\begin{array}{l}\text { Sí, y lo uso } \\
\text { frecuentemente. } \\
9.5^{2}\end{array}$ & $\begin{array}{l}\text { Sí, pero no lo } \\
\text { empleo. } \\
9.5^{2}\end{array}$ & $\begin{array}{l}\text { No. Nunca lo } \\
\text { he usado. } \\
78.57\end{array}$ \\
\hline $\begin{array}{l}\text { ¿Ha escuchado alguna vez el } \\
\text { término Realidad Aumentada? }\end{array}$ & Sí: 47.62 & & No: 52.38 \\
\hline $\begin{array}{l}\text { ¿Sabe en qué consiste la Realidad } \\
\text { Aumentada? }\end{array}$ & Sí: $35 \cdot 71$ & & No: 64.29 \\
\hline $\begin{array}{l}\text { ¿Ha empleado la realidad } \\
\text { aumentada en la enseñanza? }\end{array}$ & Sí: 7.14 & & No: 92.86 \\
\hline
\end{tabular}

Tabla 1. Resultados de la encuesta sobre Nuevas Tecnologías y Creación de Contenido Digital

Con los datos obtenidos se puede observar que los profesores emplean las nuevas tecnologías en el aula. Sin embargo su conocimiento sobre la tecnología de RA es escaso, a pesar de que la mitad de los profesores encuestados han oído hablar de la RA, únicamente el 7.14\% de ellos la han empleado en alguna ocasión (no necesariamente en la docencia). Una de las más importantes características de la RA 
es la representación de objetos tridimensionales, pero el desarrollo de estos objetos presenta grandes dificultades en distintos aspectos como son el propio desarrollo o implementación del objeto o el empleo de software específico para ello, el cual no es empleado por la mayoría de los profesores $(78.57 \%$ de los profesores nunca ha utilizado un software de desarrollo de objetos 3D).

Por lo tanto para potenciar o promover el uso de esta tecnología es necesario permitir incorporar de una forma sencilla otro tipo de elementos virtuales como videos, imágenes, música etc., a parte de los objetos $3 \mathrm{D}$ propios de la $\mathrm{RA}$, además las herramientas de RA que se empleen deberán ser sencillas e intuitivas de forma que los profesores se vean alentados a incluir contenidos digitales aumentados en sus clases.

Tal y como hemos comentado con anterioridad, no todas las herramientas tienen el mismo cometido, es decir, no todas las herramientas de RA son adecuadas para la educación.

Las aplicaciones de RA orientadas a la educación, han de cumplir una serie de premisas y/o características expuestas por Liarokapis (2010), quien menciona las siguientes condiciones:

- Debe ser un sistema robusto.

- Debe proporcionar un aprendizaje claro y conciso.

- El docente debe ser capaz de introducir nueva información de un modo simple y efectivo.

- Debe proporcionar una interacción sencilla entre el profesor y el estudiante.

- El proceso tecnológico debe ser transparente tanto para el profesor como para sus alumnos.

La mayoría de las aplicaciones de RA orientadas a la educación únicamente se centran en un aspecto específico o en un área en concreto como por ejemplo las matemáticas, la física, química, etc. Los contenidos de estas aplicaciones son generalmente estáticos, es decir, son los especificados por el programador a la hora de desarrollar la aplicación, por lo que hace que la tarea de añadir nuevos contenidos o actualizar los existentes sea una tarea complicada y en ocasiones imposible de realizar por parte de los profesores que las utilizan. 
En el lado opuesto están aquellas otras aplicaciones que son fáciles de manejar y que permiten añadir contenidos nuevos, son aquellas denominadas de propósito general; sin embargo no están orientadas a la educación, y por lo tanto carecen de ciertas funciones específicas como por ejemplo el seguimiento del aprendizaje, la contextualización de los contenidos o una posible evaluación de los mismos.

En la Tabla 2 hemos realizado una clasificación de las aplicaciones de RA atendiendo a si estas aplicaciones permiten una sencilla incorporación o gestión de contenido y si permiten interacción con el contenido.

\begin{tabular}{|c|c|c|}
\hline & Abiertas & Cerradas \\
\hline Estáticas & $\begin{array}{l}\text { Es posible visualizar y añadir } \\
\text { nuevos contenidos. } \\
\text { ANDAR: Android Augmented } \\
\text { Reality (AndAR, 2012). } \\
\text { Aumentaty Autor (Aumentaty } \\
\text { Author, 2014). }\end{array}$ & $\begin{array}{l}\text { Sólo es posible visualizar contenidos. } \\
\text { Magic Book. (Billinghurst et al., } \\
\text { 2001). } \\
\text { RA libros de texto para enseñar Inglés } \\
\text { (Stewart Smith, 2012). } \\
\text { Sistema de realidad aumentada } \\
\text { para aprender el interior del cuerpo } \\
\text { humano (Juan et al., 2008). }\end{array}$ \\
\hline Dinámicas & $\begin{array}{l}\text { Es posible visualizar, añadir e } \\
\text { interactuar con nuevos contenidos. } \\
\text { Control de un laboratorio remoto } \\
\text { empleando la realidad aumentada } \\
\text { (Cubillo et al., 2012). } \\
\text { Aplicación de realidad aumentada } \\
\text { para enseñar energías renovables } \\
\text { (Martin et al., 2012). }\end{array}$ & $\begin{array}{l}\text { Es posible visualizar e interactuar con } \\
\text { el contenido. } \\
\text { Piano RA (Huang et al., 2011). } \\
\text { ARISE Augmented Reality in School } \\
\text { Environments (Pemberton \& Winter, } \\
\text { 2009). }\end{array}$ \\
\hline
\end{tabular}

Tabla 2. Clasificación de las Aplicaciones de Realidad Aumentada

Las aplicaciones mostradas en la Tabla 2 son todas unidireccionales y orientadas hacia los estudiantes, sin embargo ninguna de ellas facilita información sobre el aprendizaje llevado a cabo por los estudiantes, su uso, su funcionalidad o la calidad de los recursos. Otra clasificación de las herramientas de RA es la indicada por (Hampshire et al., 2006), en la que propone 2 categorías: las herramientas de autoría de RA para programadores o que requieren conocimientos de programación y por otro lado aquellas que no requieren conocimientos de programación (Seichter et al., 2008).

Tal y como se desprende de esta clasificación, el primer grupo corresponderá a aquellas herramientas donde los usuarios deben tener ciertos conocimientos de 
programación o de lenguajes de programación tales como Java, C + +, Javascript etc., o conocimientos de librerías de desarrollo de aplicaciones como pueden ser las librerías de visión por ordenador, reconocimiento de imágenes, seguimiento de patrones, posicionamiento etc. Algunos ejemplos de estas herramientas son ARToolKit, NyARToolkit, FLARToolkit, ArUco, DroidAR, D’Fusion Studio Wikitude SDK, Metaio SDK, todas ellas permiten el desarrollo de aplicaciones específicas de RA.

Por otro lado se encuentran aquellas herramientas para no programadores, donde se pueden construir aplicaciones sin escribir código. Estas herramientas permiten un desarrollo mucho más rápido, sin embargo su funcionalidad es más limitada o menos potente ya que en la mayoría de los casos no soportan la interacción (Dörner et al., 2003; Grimm et al., 2002; MacIntyre et al., 2004) o comportamientos más complejos. En el caso de que estas limitaciones se deseen solventar, será necesario incluir cierto nivel de programación, por ejemplo Layar es una aplicación donde crear experiencias con RA es sencillo, se pueden insertar videos, imágenes o contenido multimedia sin más que arrastrarlos sobre la pantalla de edición, sin embargo para añadir objetos 3D es necesario disponer de ciertos conocimientos de lenguajes de programación, otras herramientas como Aurasma permiten la incorporación de objetos $3 \mathrm{D}$ de una forma sencilla pero tienen limitada la interacción en el escalado o posicionamiento, de forma que esta no se puede llevar a cabo en tiempo real, perdiendo una de las características más importantes de la RA que es el ser aumentada y representada en tiempo real. Otra herramienta es Augment, la cual permite la interacción en tiempo real, y la inserción de objetos 3D también se realiza de forma muy sencilla, sin embargo tiene otras limitaciones como por ejemplo que el número de modelos que se pueden representar en su versión gratuita es de 3 . Por último otra de las opciones que se pueden manejar es Metaio Creator Application, en la cual los profesores pueden agregar contenidos $3 \mathrm{D}$, videos, audio y páginas web a cualquier contenido impreso, pero para poder realizar esto deberán comprar la aplicación. En la Tabla 3 se muestra un listado de las herramientas para desarrollar experiencias de RA más importantes.

\begin{tabular}{|l|l|l|}
\hline \multicolumn{1}{|c|}{ Herramientas de Autor } & \multicolumn{1}{|c|}{ Tipo de Licencia } & $\begin{array}{l}\text { Conocimientos } \\
\text { de Programación }\end{array}$ \\
\hline Argon & Licencia Comercial. & Sí \\
\hline ARToolKit & $\begin{array}{l}\text { Open source. Licencia } \\
\text { Comercial disponible. }\end{array}$ & Sí \\
\hline $\begin{array}{l}\text { AR-media } \\
\text { SketchUp }\end{array}$ & Plugin for Google \\
\hline ArUco & Comercial/ Uso libre. & No \\
\hline
\end{tabular}




\begin{tabular}{|l|l|l|}
\hline \multicolumn{1}{|c|}{ Herramientas de Autor } & \multicolumn{1}{|c|}{ Tipo de Licencia } & \multicolumn{1}{c|}{$\begin{array}{c}\text { Conocimientos } \\
\text { de Programación }\end{array}$} \\
\hline ATOMIC Authoring Tool & Open source. & No \\
\hline Aumentaty Author & Comercial/ Uso libre. & No \\
\hline Aurasma & Comercial/ Uso libre. & No \\
\hline Augment & Comercial/ Uso libre. & No \\
\hline BuildAr & $\begin{array}{l}\text { Open Source. Licencia } \\
\text { Comercial disponible. }\end{array}$ & No \\
\hline DroidAR & $\begin{array}{l}\text { Open source (licencia doble: } \\
\text { GPLv3 o comercial). }\end{array}$ & Sí \\
\hline $\begin{array}{l}\text { FLARToolKit and FLARManager } \\
\text { Adobe Flash }\end{array}$ & Open source. & Sí \\
\hline Junaio & Comercial/ Uso libre. & No \\
\hline & & $\begin{array}{l}\text { No (Para insertar } \\
\text { objetos } \\
\text { necesario } \\
\text { conocimiento } \\
\text { JSON, PHP etc. }\end{array}$ \\
\hline Layar & cierto \\
& Comercial/ Uso libre. \\
\hline LinceoVR & & No \\
\hline Metaio SDK & Licencia Comercial. & Sí \\
\hline Metaio Creator & Comercial/ Uso libre. & No \\
\hline Mixare & Licencia Comercial. & No \\
\hline NyARToolkit & Libre uso. & Sí \\
\hline SLARToolkit & Open source. & Sí \\
\hline Total Immersion - D'Fusion Studio & Open source. & Sicencia Comercial. \\
\hline Wikitude & Licencia Comercial. & Sicencia No comercial. \\
\hline VYZAR & Sorta 2 opciones \\
\hline
\end{tabular}

Tabla 3. Ejemplos de Herramientas de Realidad Aumentada

Tras estudiar las diferentes características de las herramientas descritas, se optó por desarrollar una herramienta de autoría propia, que debe ser una herramienta libre que permita añadir objetos $3 \mathrm{D}$, junto con otro tipo de contenido multimedia de una forma sencilla, intuitiva y orientada a la educación (deberá poder contextualizar los recursos virtuales y así ayudar a los alumnos a comprender lo que están visualizando). Para ello se optó por emplear el potencial de las herramientas de RA de programadores para desarrollar un entorno de RA para no programadores que cumpla con los requisitos anteriores. 


\section{ARLE-AUGMENTED REALITY LEARNING ENVIRONMENT}

Esta sección describe el Sistema ARLE (Augmented Reality Learning Environment), un entorno de aprendizaje basado en RA, el cual cubre cada una de las características mencionadas por Liarokapis (2010) y descritas en apartados anteriores. Como ya hemos mencionado, el objetivo es animar a los profesores a incorporar la tecnología de RA en sus actividades docentes, pero de una forma sencilla y transparente. Con este entorno de aprendizaje, el profesorado entre otras opciones podrá incorporar diverso contenido multimedia como video, imágenes, objetos en $3 \mathrm{D}$ e incluso objetos 3D animados (en formato MD2) a sus libros, apuntes, ejercicios, etc.

Una de las más importantes características que distingue ARLE de otras herramientas de autoría es la posibilidad que tiene el profesor de incorporar una descripción o narrativa acerca del recurso virtual que va a desarrollar. La contextualización y descripción de los recursos a través de un material de soporte facilitará a los estudiantes la comprensión y asimilación de los contenidos que están observando sea cual sea la tecnología empleada Dickey (2006). La narrativa en este caso ofrece a los estudiantes un marco cognitivo para la resolución de problemas, por lo tanto los profesores pueden preparar recursos autónomos que contengan su propia información.

Otra característica del sistema comparado con otras herramientas es que ARLE incorpora una biblioteca de recursos disponibles para los profesores que no puedan o sepan desarrollar nuevos contenidos; la biblioteca irá adquiriendo nuevos recursos a medida que otros usuarios los vayan incorporando, de este modo podremos en un futuro encontrar recursos de cualquier índole o tema.

Por último, ARLE proporciona a los usuarios la opción de incorporar cuestiones de respuesta múltiple (Multiple Choice Question) a los recursos virtuales que verá el usuario. El sistema ofrece esta opción debido a que los estudiantes pueden obtener a través de estos test, un feedback instantáneo e individual (Gibbs \& Simpson, 2004) sobre su aprendizaje. Esto puede ser útil tanto para el alumno como para el profesor ya que el estudiante puede afianzar sus conocimientos y clarificar aquellos puntos considerados más importantes. No obstante, no podemos olvidar que el feedback que podemos llegar a obtener de un móvil, tablet o un PC no es el mismo que el que nos daría un profesor de carne y hueso, pero los estudiantes lo encuentran útil (Van Der Vleuten, Cees PM, 1996); de hecho algunos de ellos incluso lo prefieren ya que es flexible, pueden trabajar con ello las veces que se desee y realizarlo a cualquier hora. Otra característica de este tipo de preguntas es que los resultados son cuantificables, 
esto hace posible analizar el nivel que los estudiantes adquieren en cada pregunta, de modo que el profesor sea capaz de detectar y analizar posibles áreas en las que los estudiantes muestren lagunas o presenten mayores dificultades bien por su contenido o por su propia problemática (Bridgeman, 1992). Un test de respuesta múltiple cuidadosamente diseñado puede servir de herramienta para evaluar el aprendizaje. En la Tabla 4 se presenta el nivel de las preguntas de respuesta múltiple en la tabla de niveles de la taxonomía de Bloom sobre los objetivos educativos (Govindasamy, 2001).

\begin{tabular}{|l|l|l|l|l|l|}
\hline $\begin{array}{c}\text { Nivel de Bloom: } \\
\text { nivel cognitivo } \\
\text { de desarrollo } \\
\text { de habilidades }\end{array}$ & $\begin{array}{c}\text { Preguntas } \\
\text { Respuesta } \\
\text { Múltiple }\end{array}$ & $\begin{array}{c}\text { Entrada } \\
\text { Texto }\end{array}$ & $\begin{array}{c}\text { Coinci- } \\
\text { dencias }\end{array}$ & $\begin{array}{c}\text { Casos } \\
\text { de } \\
\text { Estudio }\end{array}$ & Simulación \\
\hline Conocimiento & Sí & Sí & Sí & No & No \\
\hline Comprensión & Sí & Sí & Sí & Sí & No \\
\hline Aplicación & Sí & Sí & No & Sí & No \\
\hline Análisis & Sí & No & No & Sí & Sí \\
\hline Síntesis & Sí & No & No & Sí & Sí \\
\hline Evaluación & Sí & No & No & Sí & Sí \\
\hline
\end{tabular}

Tabla 4. Tipos de Cuestiones para medir los distintos niveles de habilidades Cognitivas

\section{Descripción del Sistema ARLE}

El Sistema está basado en una arquitectura cliente-servidor, en la cual los datos y la información se envían al dispositivo móvil (tablet, Smartphone etc.) una vez que la aplicación se ha iniciado. El dispositivo móvil que actuará como receptor de la información puede acceder e interactuar con los recursos de RA, por ejemplo, se pueden reproducir objetos $3 \mathrm{D}$, objetos $3 \mathrm{D}$ animados, se pueden reproducir videos, escalar objetos, contestar a los test sobre los recursos que están siendo visualizados, etc.

Los usuarios tienen acceso a la plataforma web para poder añadir nuevos recursos virtuales y desde la misma plataforma podrán incorporar las cuestiones tipo test a esos recursos, añadir una descripción que sirva de contextualización al recurso y así poder crear un recurso virtual aumentado autónomo, de forma que cualquier usuario que lo vea pueda saber a qué está haciendo referencia ese objeto, qué conceptos pretende aclarar, cuáles son los puntos más interesantes que se pretenden observar o qué características son las más destacables. Por último, todos los nuevos recursos que se van añadiendo a través de la plataforma web son incorporados a la biblioteca 
de recursos accesibles por cualquier usuario de forma que estén disponibles para profesores, alumnos o cualquier persona interesada.

El sistema se ha desarrollado empleando la tecnología de RA de la empresa Metaio (Metaio Augmented Reality Products \& Solutions, 2011) junto con otra serie de herramientas necesarias para desarrollar el entorno de aprendizaje como por ejemplo Android SDK, PHP, etc.

La Figura 1 muestra un ejemplo de utilización de la aplicación móvil, donde un alumno visualiza el modelo tridimensional de una torre de alta tensión. Los estudiantes de electricidad y electrónica emplean este recurso para identificar los distintos componentes de estas torres, evitando viajar hasta una torre real, el profesor añade una descripción de los tipos de elementos disponibles en ella, así como una serie de preguntas que permiten identificar si el alumno ha adquirido esos conocimientos.

Otro ejemplo se encuentra en la Figura 2, que presenta una placa de circuito impreso de un circuito estudiado por los alumnos de electrónica en la que se muestra el empleo de los microcontroladores. Con el sistema ARLE, los alumnos no solo visualizan y manipulan la representación de la placa tal y como se vería una vez fabricada, sino que obtienen información adicional de los componentes que la forman así como de los elementos necesarios para su funcionamiento.

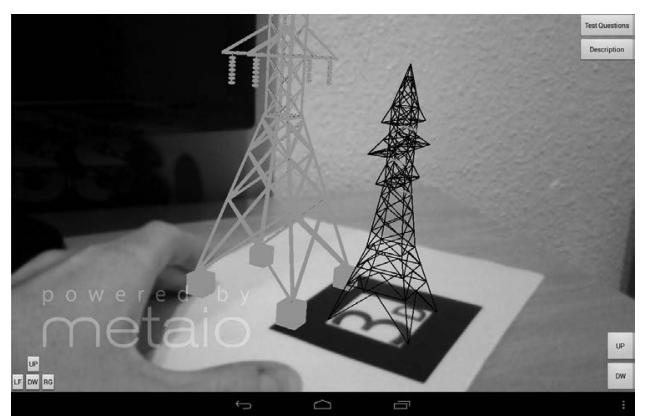

Figura 1. Ejemplo de un objeto en $3 \mathrm{D}$, en este caso es una torre de voltaje de alta tensión

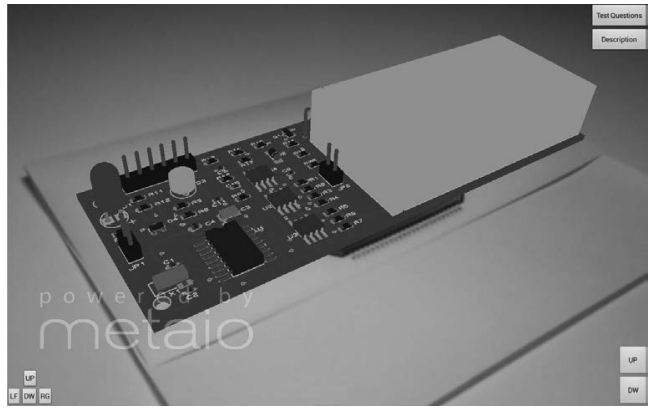

Figura 2. Ejemplo de un objeto en $3 \mathrm{D}$, en este caso se trata de una placa de circuito impreso el cual emplea un microcontrolador, el dsPIC33FJ12GP2O1 


\section{Plataforma Web de ARLE. Preparación de un Recurso Aumentado}

El procedimiento para preparar un recurso virtual aumentado a través de la plataforma web ARLE es el siguiente: El profesor debe preparar o desarrollar un recurso virtual -por ejemplo, si el recurso virtual que será añadido al sistema de RA es un video, se deberá transformar el video al formato adecuado de la aplicación ARLE; para hacer esto se dispone de software libre de fácil uso como por ejemplo aTubeCatcher, el cual permite convertir videos al formato de ARLE. Si lo que se desea por el contrario es añadir un objeto tridimensional, el objeto debe tener el formato de los objetos OBJ o MD2, estos también pueden realizarse con software gratuito como Blender, Google SketchUp o con software comercial como 3D Studio, Maya. También existen modelos de objetos 3D que se pueden descargar libremente de internet (sus desarrolladores han dado libertad para usarlos): Estos modelos se pueden encontrar en distintas fuentes como por ejemplo: Google 3D Warehouse, TurboSquid, 3 $\mathrm{dm} 3$, Great buildings, DLegend, 3DXtras, todos ellos ofrecen modelos libres sobre diferentes áreas o temas como mecánica, electrónica, construcciones, modelos de personas, etc.

Una vez que tenemos el modelo o el recurso virtual adecuado es el momento de añadirlo a la plataforma ARLE. La Figura 3 muestra la plataforma web ARLE y los pasos a seguir para añadir el recurso virtual, su descripción o las preguntas test. La Figura 4 muestra la forma de incluir estas preguntas tipo test (el número de preguntas que el profesor podrá añadir es ilimitado). 


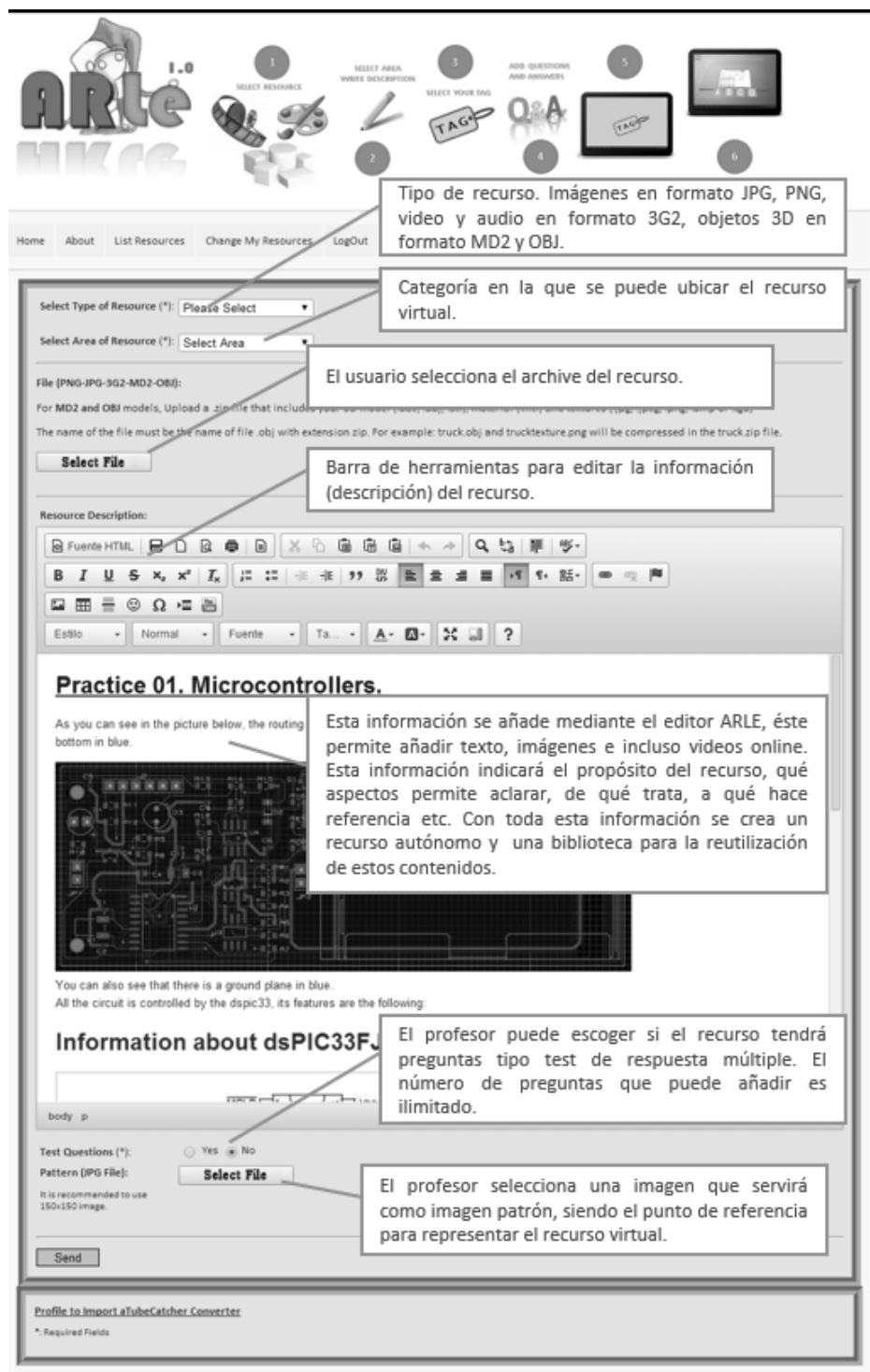

Figura 3. Pasos a seguir para incorporar un recurso virtual a la plataforma ARLE y dotarle de Realidad Aumentada 


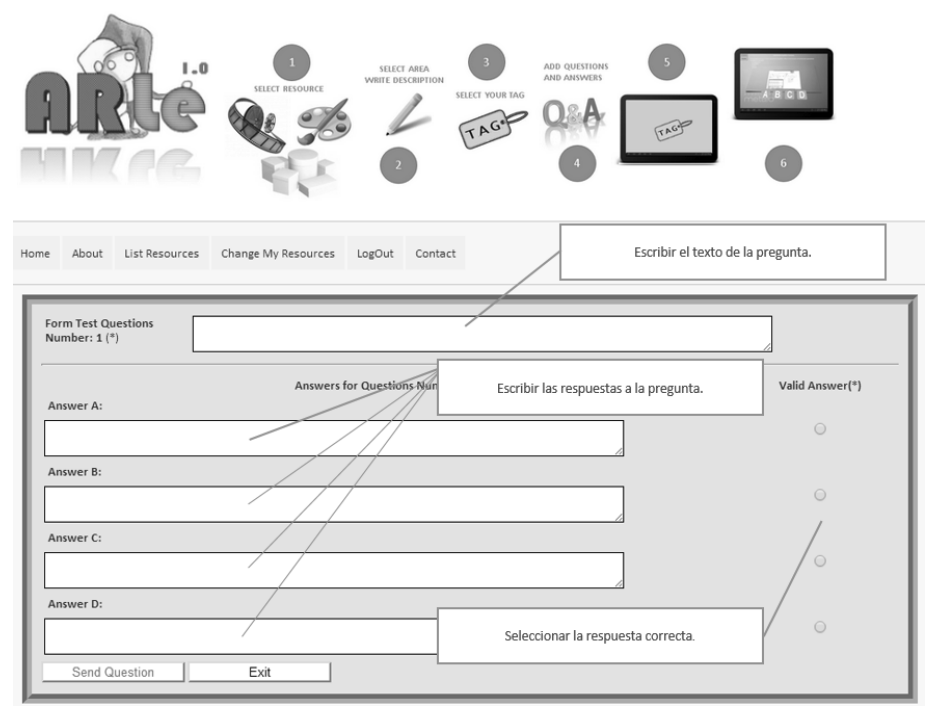

Figura 4. Plataforma Web ARLE. Ventana para editar las preguntas tipo test de respuesta múltiple. Se escribirá la pregunta así como las posibles respuestas y se marcará aquella respuesta correcta

Finalmente y tal y como se ha indicado en apartados anteriores, una vez que el recurso es añadido pasa a formar parte de la biblioteca de recursos de ARLE, así cualquier usuario podrá reutilizar este recurso o compartirlo para que futuros profesores lo empleen en su docencia, esto incrementará la eficiencia de los contenidos a través de la reutilización.

La Figura 5 muestra una serie de recursos virtuales aumentados que han ido añadiéndose por distintos profesores en la categoría de Tecnología. Si un profesor o estudiante desea emplear estos recursos, únicamente deberá descargar la imagen que sirve como patrón (TAG) y ponerla sobre sus apuntes, libros, ejercicios, etc.

El alumno con su dispositivo móvil (empleando la aplicación ARLE) identificará ese patrón y automáticamente se superpondrá sobre el patrón el recurso virtual asociado al mismo, con lo que podrá visualizarse un objeto $3 \mathrm{D}$, un video, etc. 


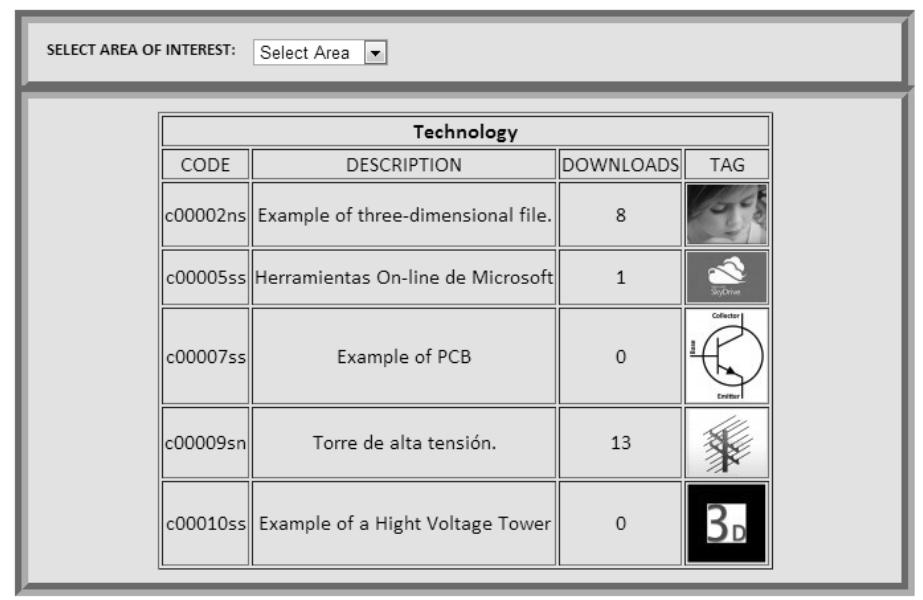

Figura 5. Una biblioteca de recursos organizados por categorías o áreas de interés. Todos los recursos añadidos al sistema ARLE están disponibles para otros usuarios

\section{Herramienta de Visualización ARLE}

El modo de operación de la aplicación móvil ARLE es el siguiente:

- El usuario (estudiante), instala la aplicación en su dispositivo Android (Tablet, Smartphone). Una vez iniciada la aplicación el estudiante enfocará la cámara del dispositivo sobre sus apuntes, libro, etc., proporcionados por el profesor. La aplicación detectará la imagen que fue escogida por el profesor como patrón y superpondrá el recurso virtual sobre él, comenzando la experiencia con la RA.

- La interacción entre el estudiante y la aplicación se realiza a través de los botones de RA o mediante gestos. La interacción puede ser arrastrar el objeto 3D sobre la pantalla, mover el objeto con botones, escalar los objetos, reproducir videos, etc.

- El estudiante puede obtener información adicional sobre el recurso que está visualizando si pulsa sobre el botón de Descripción; este botón muestra la información que el profesor añadió al recurso y que sirve para contextualizar el aprendizaje que se está llevando a cabo. Cuando el alumno pulse sobre el botón se mostrará una ventana a la izquierda de la pantalla en la que aparecerá dicha información que podrá ser una simple descripción o bien podrá contar con todos los recursos multimedia que se deseen como texto, 
imágenes e incluso videos on-line. En la Figura 6 se muestra un ejemplo del tipo de información que se puede encontrar.

Finalmente, si el profesor añadió preguntas tipo test al recurso virtual, el alumno tendrá disponible un botón en la aplicación denominado Test. Este botón hará que al pulsarse aparezcan sobre la pantalla las preguntas introducidas por el profesor, estas preguntas y respuestas aparecerán en forma de botones aumentados denominados A, B, C y D.

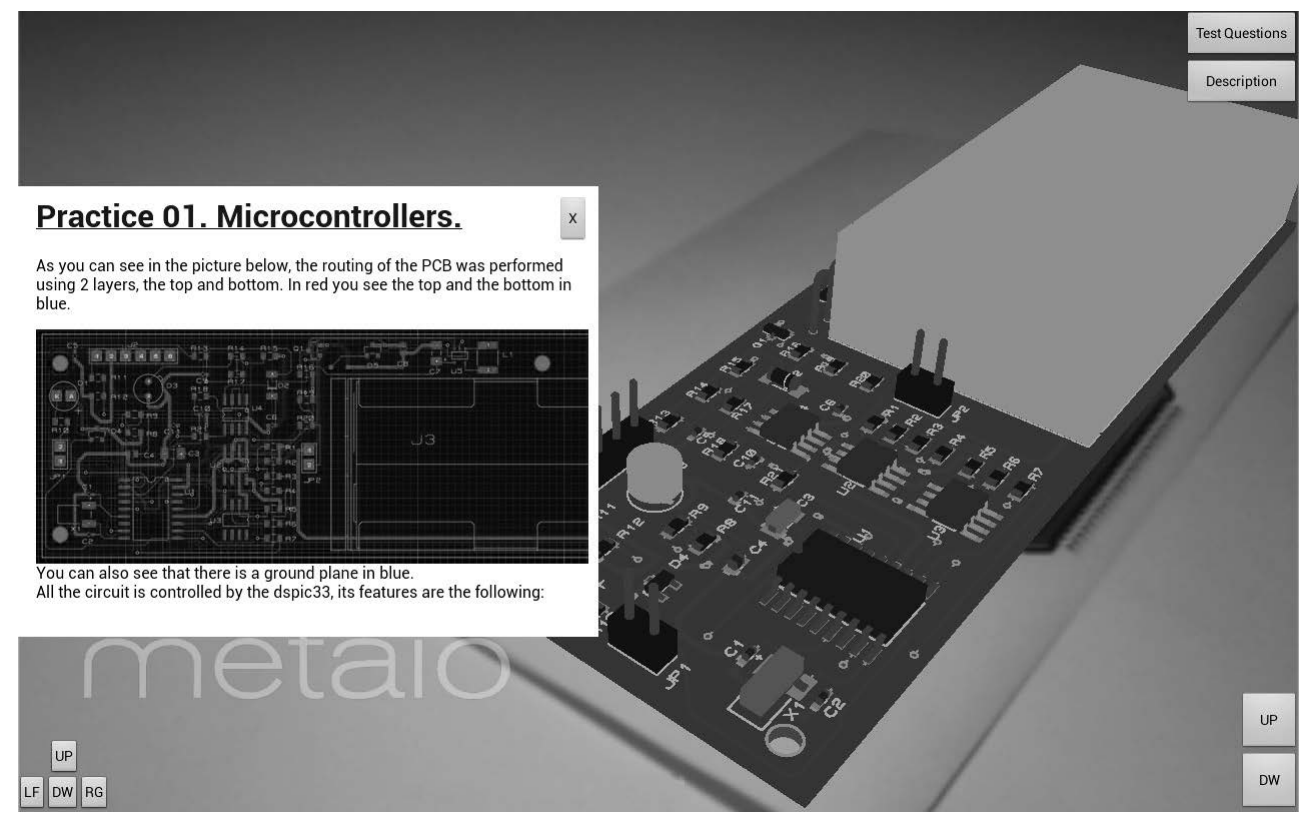

Figura 6. El estudiante está visualizando un objeto tridimensional (PCB - Placa de Circuito Impreso) e interactuando con ella. Tras pulsar sobre el botón Descripción obtendrá la información relativa al objeto en la cual se puede reflejar qué es, para qué sirve etc., es decir la contextualización del recurso de aprendizaje

La Figura 7, Figura 8 y Figura 9 muestran como un objeto 3D (en este caso un barco de vela) puede ser manipulado por el usuario (puede ser arrastrado, movido, escalado, etc.). También existen cuatro pequeños botones en la parte inferior izquierda de la pantalla con los cuales se puede efectuar un posicionamiento más preciso del objeto. 


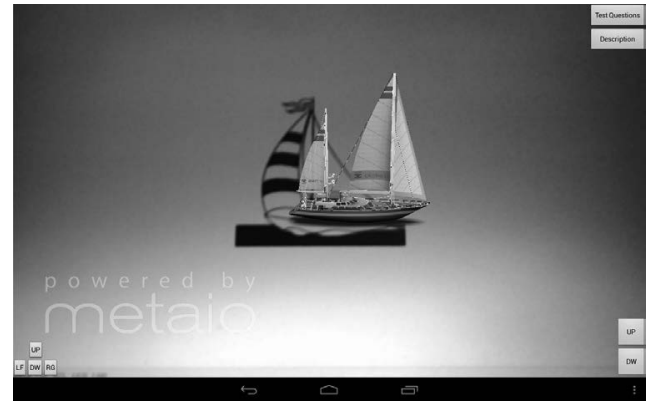

Figura 7. Un objeto 3D se superpone sobre el patrón que ha sido escogido

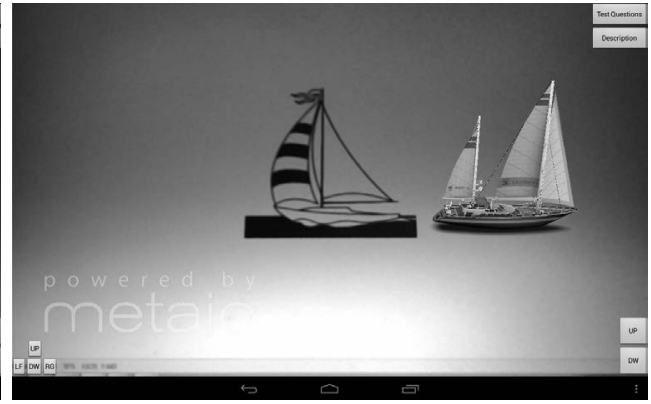

Figura 8. En este caso se muestra la acción de arrastrar el objeto a la derecha del patrón. El usuario arrastra con su dedo el objeto hasta la posición deseada de la pantalla

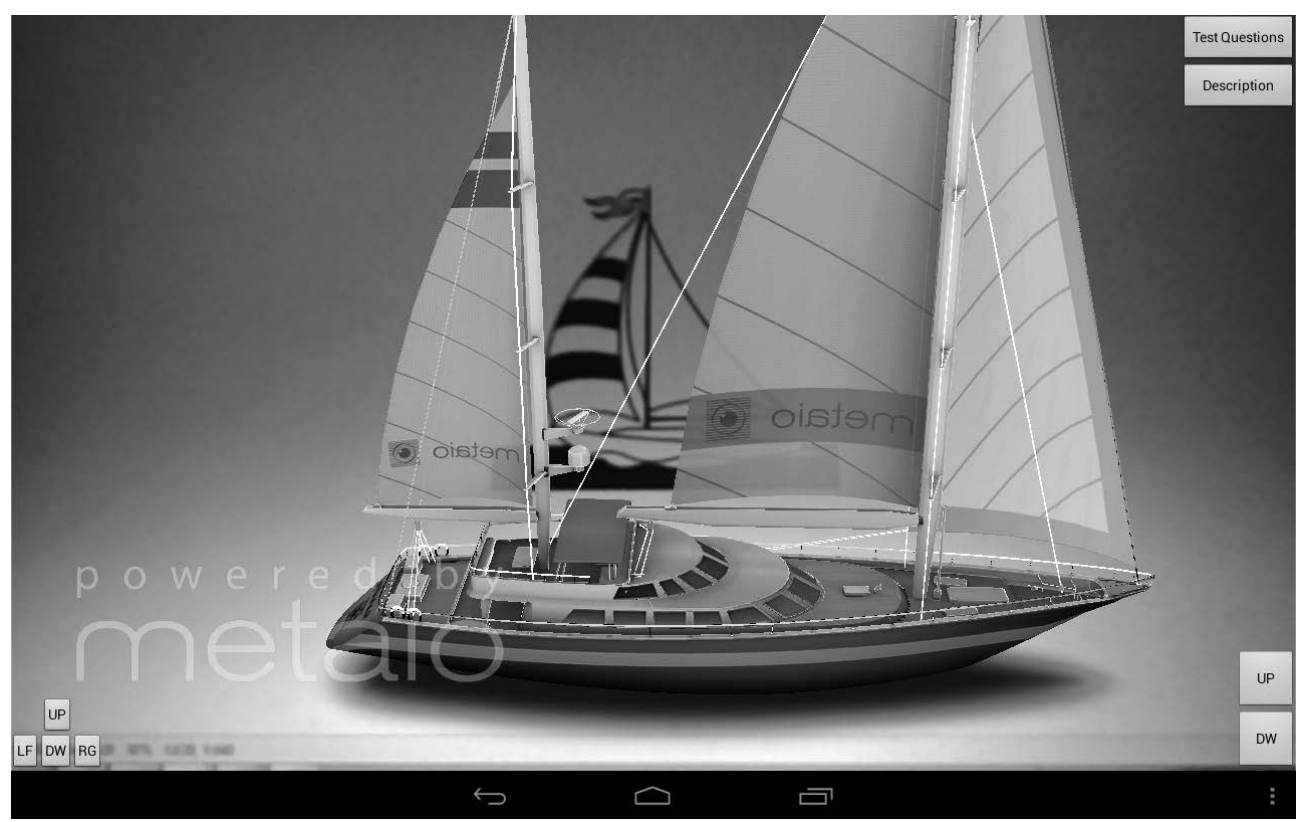

Figura 9. En este caso se ha escalado el objeto 3D usando los botones UP\&DOWN en la parte inferior derecha de la pantalla

\section{Experimentación}

Para comprobar tanto el funcionamiento de la aplicación como su uso en educación, se ha realizado un experimento con un grupo de profesores de un Centro Integrado de Formación Profesional ubicado en España. El experimento consistió en desarrollar un recurso virtual y ofrecer este recurso a sus estudiantes añadiéndolo a 
la aplicación ARLE y por lo tanto dotándolo de RA. Para el experimento se dispuso de la colaboración de 2 profesores y 44 alumnos.

El experimento se basó en emplear el recurso educacional denominado Napo. Napo es una idea original de un pequeño grupo de profesionales de la comunicación del sector de la SST y pertenece a Via Storia, productora con sede en Estrasburgo (Francia) cuyo objetivo era crear productos informativos de alta calidad que pudiesen traspasar las fronteras nacionales y llegar a las diferentes culturas e idiomas, para abordar las necesidades prácticas de las personas en el trabajo.

El recurso digital fue diseñado para adaptar los contenidos curriculares del módulo "Formación y Orientación Laboral" de una forma amena, sencilla y flexible, para reforzar la enseñanza de dicha materia. Estos recursos digitales incluyen aspectos como: la educación en la salud personal y social (PHSE-Personal, Social, Health and Economic), Ciencia, seguridad vial, el aprendizaje de idiomas y de las Artes, etc.

La Figura 10, Figura 11, Figura 12 y Figura 13 muestran la utilización de la aplicación móvil sobre una tablet con el sistema Android. Estas imágenes fueron tomadas mientras los alumnos interactuaban con la aplicación y con el recurso digital incorporado por los profesores. Una vez que la aplicación móvil reconoció el patrón que los profesores incorporaron a sus apuntes o ejercicios, el recurso digital (video de Napo), se superpuso sobre dicho patrón. En el caso mostrado en la Figura 12, al reconocer el patrón aparece un botón de PLAY el cual indica que se puede comenzar a reproducir el video, los alumnos pulsaron sobre él y comenzó la reproducción (Figura 13). El alumno siempre tiene disponible las posibles aclaraciones que introdujo el profesor en el recurso y que sirven para contextualizarlo; por otro lado como el profesor decidió incorporar preguntas test al recurso, se habilitó de forma automática en la aplicación un botón denominado TEST. Al pulsar sobre el botón TEST, comienzan a aparecer las preguntas asociadas al recurso (estas se representan en color amarillo tal y como se puede observar en la Figura 14). Las preguntas tienen 4 posibles respuestas, la respuesta correcta se seleccionará a través de los botones A, B, C o D. Si el usuario pulsa sobre la respuesta correcta, se le dará paso a la siguiente pregunta (como si de un juego de niveles se tratara); si por el contrario la respuesta es incorrecta se irán acumulando sus fallos hasta que acierte y así pueda ver la respuesta correcta y por qué ha fallado (Figura 15). 


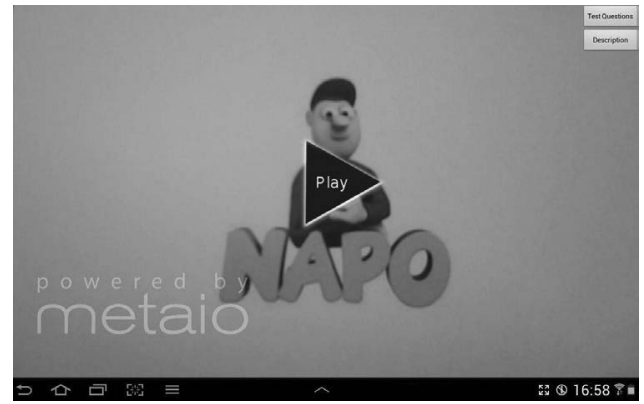

Figura 10. Reconocimiento del Patrón - El patrón es reconocido y el recurso virtual se superpone sobre él. En este caso el recurso virtual es un botón de PLAY el cual permite interactuar al usuario con un video en formato $3 \mathrm{G} 2$

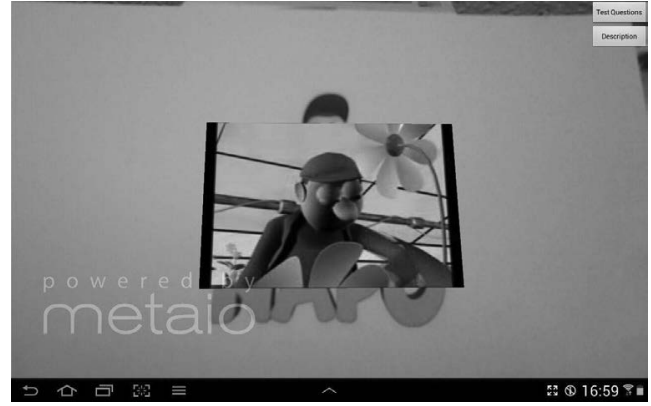

Figura 11. El usuario toca el botón aumentado (PLAY) y comienza la reproducción del video. El video podrá redimensionarse empleando los botones de escalado, así se podrá aumentar de tamaño o hacer más pequeño

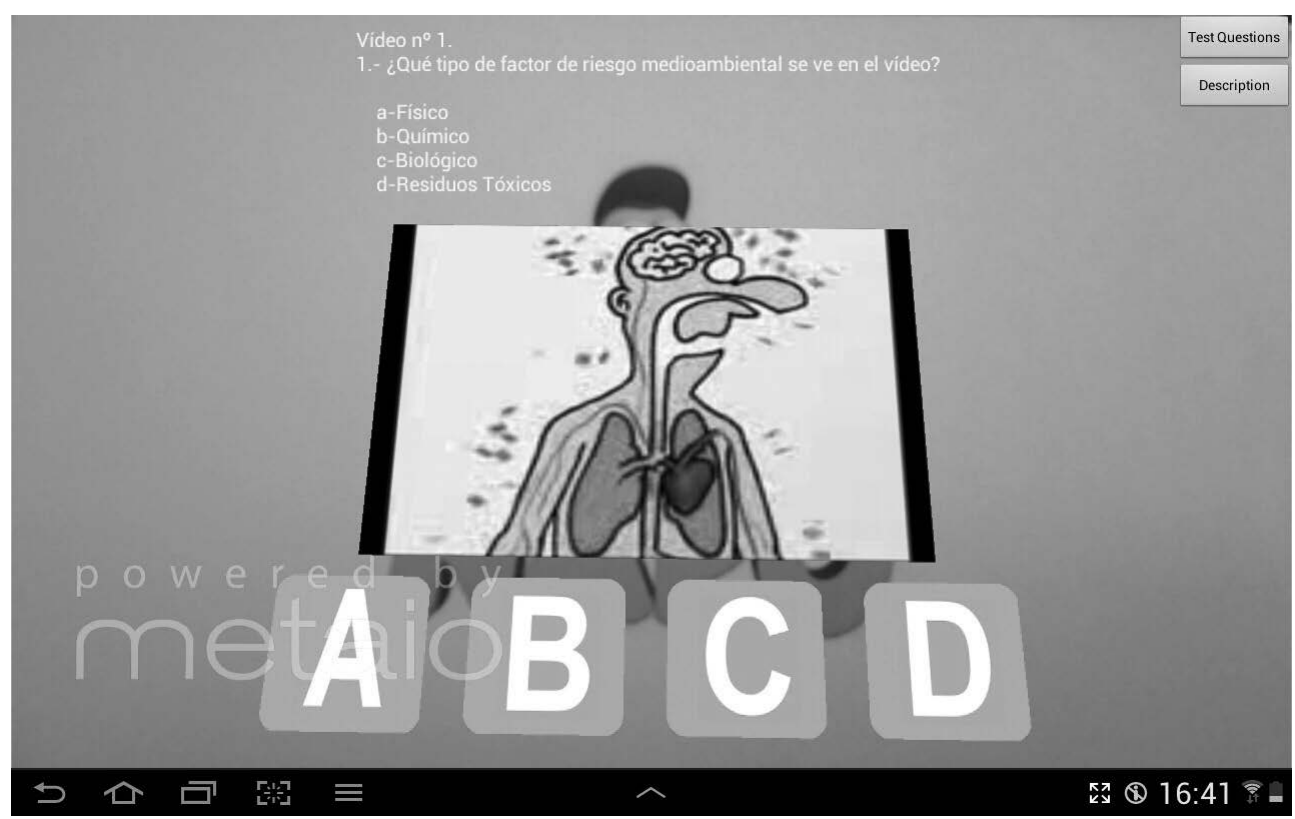

Figura 12. El usuario pulsa sobre el botón de TEST el cual hace que aparezcan tanto las preguntas test de respuesta múltiple (texto en color amarillo en la parte superior de la pantalla), como las posibles respuestas, A, B, C y D (botones representados con RA) 


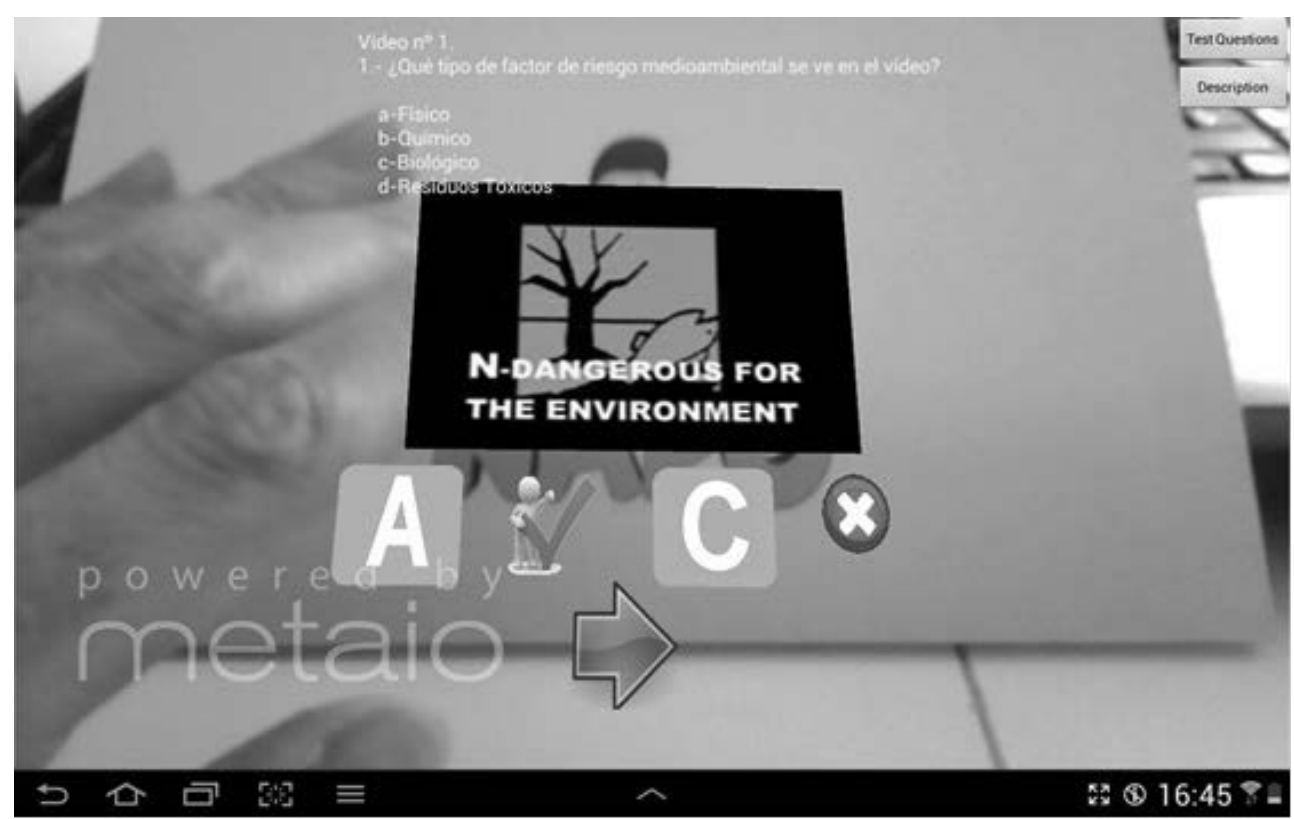

Figura 13. Cuando el usuario responde de forma correcta, una nueva pregunta aparecerá en la pantalla. Si por el contrario la respuesta es incorrecta se representará con un aspa y no se permitirá continuar con la siguiente cuestión hasta acertar

Para analizar el funcionamiento de la aplicación y su usabilidad, se desarrolló un cuestionario con 15 preguntas (las respuestas a cada pregunta se valoran del 1 al 5 , donde el 1 se corresponde con la puntuación más baja o nunca y el 5 a la más alta $o$ siempre). La Tabla 5 refleja el cuestionario que se realizó junto con el análisis de los resultados obtenidos y la desviación estándar de los mismos.

\begin{tabular}{|l|l|l|l|}
\hline & PREGUNTA & $\begin{array}{l}\text { MEDIA } \\
\text { (Max 5, } \\
\text { Min 1) }\end{array}$ & $\begin{array}{l}\text { DESVIACIÓN } \\
\text { ESTANDAR }\end{array}$ \\
\hline $\mathbf{1}$ & Experiencia previa con realidad aumentada & 2.27 & 1.17 \\
\hline $\mathbf{2}$ & Facilidad en el manejo de la aplicación & 4.18 & 0.89 \\
\hline $\mathbf{3}$ & Tiempo de respuesta de la aplicación & 3.50 & 0.84 \\
\hline $\mathbf{4}$ & Funcionalidad & 3.77 & 1.00 \\
\hline $\mathbf{5}$ & ¿Cómo ha sido la interacción con el usuario? & 4.09 & 0.73 \\
\hline $\mathbf{6}$ & Puntúa el diseño de la aplicación & 3.86 & 0.97 \\
\hline
\end{tabular}




\begin{tabular}{|l|l|l|l|}
\hline & PREGUNTA & $\begin{array}{l}\text { MEDIA } \\
\text { (Max 5, } \\
\text { Min 1) }\end{array}$ & $\begin{array}{l}\text { DESVIACIÓN } \\
\text { ESTANDAR }\end{array}$ \\
\hline 7 & $\begin{array}{l}\text { ¿Cómo valoras la usabilidad de la aplicación para el } \\
\text { estudio o para preparar el curso? }\end{array}$ & 3.64 & 1.02 \\
\hline $\mathbf{8}$ & $\begin{array}{l}\text { ¿Me ha permitido tener una mejor comprensión de los } \\
\text { contenidos teóricos impartidos? }\end{array}$ & 3.64 & 0.98 \\
\hline $\mathbf{9}$ & $\begin{array}{l}\text { ¿Es más entretenido y divertido que el estudio con } \\
\text { apuntes o libros? }\end{array}$ & 4.45 & 0.58 \\
\hline $\mathbf{1 0}$ & $\begin{array}{l}\text { ¿Encuentras útil disponer de los contenidos y de la } \\
\text { aplicación a cualquier hora y en cualquier lugar? }\end{array}$ & 3.77 & 0.90 \\
\hline $\mathbf{1 1}$ & $\begin{array}{l}\text { ¿Es útil para consolidar conocimientos o conceptos } \\
\text { después de una sesión presencial con el tutor? }\end{array}$ & 4.00 & 0.74 \\
\hline $\mathbf{1 2}$ & $\begin{array}{l}\text { ¿Este tipo de aplicación debería ser usado en otras } \\
\text { áreas? }\end{array}$ & 4.18 & 0.78 \\
\hline $\mathbf{1 3}$ & ¿Lo recomendarías a otros estudiantes? & 4.05 & 0.77 \\
\hline $\mathbf{1 4}$ & Estoy satisfecho con la aplicación & 4.00 & 0.80 \\
\hline $\mathbf{1 5}$ & ¿Cuál es tu opinión global sobre la aplicación? & 3.95 & 0.71 \\
\hline
\end{tabular}

Tabla 5. Resultados del cuestionario sobre funcionabilidad y usabilidad de la Aplicación

Además del cuestionario anterior también se formularon dos preguntas de respuesta abierta cuyas respuestas son las mostradas en la Tabla 6:

\begin{tabular}{|l|l|}
\hline \multicolumn{1}{|c|}{ Revisión de la Aplicación } & Posibilidades de Mejora \\
\hline $\begin{array}{l}\text { La aplicación es entretenida y su uso para aprender los } \\
\text { contenidos teóricos es sencillo y muy entretenido. }\end{array}$ & $\begin{array}{l}\text { Añadir la posibilidad de } \\
\text { avanzar o rebobinar los } \\
\text { videos. }\end{array}$ \\
\hline $\begin{array}{l}\text { Es un entorno de aprendizaje que puede ayudar a revisar el } \\
\text { material explicado en clase de una forma más entretenida. }\end{array}$ & $\begin{array}{l}\text { Posibilidad de tener pantalla } \\
\text { complete en los videos. }\end{array}$ \\
\hline $\begin{array}{l}\text { La aplicación es buena y conveniente porque los estudiantes } \\
\text { podemos aprender por nosotros mismos en cualquier sitio } \\
\text { y a nuestro ritmo. }\end{array}$ & $\begin{array}{l}\text { Salvar los resultados de los } \\
\text { test en el dispositivo además } \\
\text { de guardarlos en el servidor. }\end{array}$ \\
\hline La aplicación es intuitiva. & $\begin{array}{l}\text { Añadir nuevos formatos de } \\
\text { objetos 3D. }\end{array}$ \\
\hline $\begin{array}{l}\text { Las preguntas tipo test hacen que la aplicación sea más } \\
\text { dinámica y entretenida. }\end{array}$ & \\
\hline
\end{tabular}




\begin{tabular}{|l|l|}
\hline \multicolumn{1}{|c|}{ Revisión de la Aplicación } & Posibilidades de Mejora \\
\hline Es similar a un juego. & \\
\hline Es útil e interesante. & \\
\hline $\begin{array}{l}\text { Debería emplearse en clase para consolidar los } \\
\text { conocimientos. }\end{array}$ & \\
\hline Debería emplearse en otras asignaturas. & \\
\hline Muy sencilla. & \\
\hline Ayudar a comprender "las cosas" con menos esfuerzo. & \\
\hline
\end{tabular}

Tabla 6. Respuestas a las preguntas de respuesta abierta

\section{CONCLUSIONES}

Como se ha mencionado en los apartados anteriores existen una gran variedad de herramientas para desarrollar experiencias de RA y algunas de ellas incluso permiten añadir objetos 3D de una forma sencilla. Sin embargo las herramientas de RA empleadas en educación son generalmente específicas para un área en concreto, mientras que aquellas otras más generalistas están limitadas a la reproducción de contenido virtual y no tienen ciertas cualidades educativas como la retroalimentación, el seguimiento del aprendizaje o la contextualización.

Este artículo presenta una herramienta de autor de RA orientada a la educación que incluye: (1) la posibilidad de incorporar distintos recursos multimedia de una forma sencilla, (2) la habilidad para incorporar descripciones o contextualización a los recursos que serán visualizados por los estudiantes (de este modo se proporciona a los estudiantes información adicional sobre el recurso, y por lo tanto, el recurso puede ser adaptado o personalizado a las necesidades de los estudiantes convirtiéndose en un recurso autónomo), (3) presenta la posibilidad de incluir cuestiones de respuesta múltiple, que proporcionan al usuario final una retroalimentación instantánea e individualizada sobre los contenidos del recurso (Gibbs \& Simpson, 2004), y (4) una biblioteca de recursos virtuales desde la cual todos los recursos están disponibles para cualquier usuario de una forma sencilla y transparente.

Finalmente, el hecho de que los alumnos tengan disponibles en tiempo real el recurso y la contextualización del mismo a través de la RA, les permite recordar qué conceptos pueden ser más importantes o aquellos que presentan más interés. Por lo tanto, no solo sirve como una herramienta de aprendizaje sino como una herramienta que permite ahorrar tiempo en la búsqueda de contenido e información, los recursos pueden ser visualizados en cualquier momento y en cualquier lugar, y 
la contextualización clarifica el cometido de dichos recursos; todo ello conlleva a facilitar la síntesis, esquematización y asimilación de los conceptos.

Tras el experimento realizado se pudo concluir que el sistema ARLE ayudó a los estudiantes que lo emplearon a asimilar y estudiar los contenidos teóricos impartidos por los profesores. Si los estudiantes disponen de herramientas específicas para su educación que permitan la personalización y adaptación de contenidos adecuados a las características de cada uno de ellos, los profesores podrían obtener resultados más homogéneos dentro de la heterogeneidad del alumnado que existe actualmente en las aulas.

Respecto a la usabilidad y funcionalidad del sistema, los estudiantes y profesores manifestaron que es adecuada, tal y como se puede observar en los resultados obtenidos, donde la aplicación obtiene una puntuación de 3.95 sobre 5 . Los estudiantes también indicaron que a pesar de su buena funcionalidad existen aspectos susceptibles de mejora como son los mostrados en la Tabla 6.

Por otro lado, los profesores también valoraron de forma positiva la aplicación, destacando su velocidad de respuesta así como la simplicidad para incorporar recursos virtuales a libros, notas, etc., además de disponer de la posibilidad de emplear otros recursos creados por otros usuarios. En sus valoraciones se centraron en la opción de integrar en una sola aplicación la conversión entre los formatos de video o de objetos $3 \mathrm{D}$, para que desde la misma plataforma se puedan convertir los recursos al formato adecuado de la misma. También remarcaron la complejidad para poder desarrollar nuevos contenidos virtuales, especialmente en el caso de objetos tridimensionales. Por último señalaron que la incorporación de descripciones o narrativa a los recursos virtuales los convierte en recursos educativos en sí mismos, aclarando no solo los conceptos que el recurso pretende mostrar sino aquellos a los que contextualiza o complementa.

Como resumen podemos decir que con la RA y con la información que se puede incorporar a los recursos virtuales aumentados se facilita la comprensión de los estudiantes sobre el tema que está siendo tratado por el profesor. Se puede observar que el $77 \%$ de los estudiantes están satisfechos con la aplicación y que el 95.5\% de ellos la considera interesante. Este proyecto pretende ser además de una herramienta de RA, una herramienta para la enseñanza y el aprendizaje que hace uso de la RA para facilitar la comprensión de los alumnos y la enseñanza de los profesores frente a otras herramientas cuya labor es únicamente la de reproductor de contenidos virtuales. 


\section{REFERENCIAS BIBLIOGRÁFICAS}

Ally, M. (2009). Mobile Learning: Transforming the Delivery of Education and Training (Au Press), UBC Press.

AndAR (2012). Android Augmented RealityGoogle Project.

Andújar, J. M.; Mejías, A.; Márquez, M. A. (2011). Augmented Reality for the Improvement of Remote Laboratories: An Augmented Remote Laboratory IEEE Transactions on Education, 54 (3), (492-500).

Aumentaty Author (2014). Tool for Augmented Reality.

Azuma, R. (1997). A Survey of Augmented Reality. Teleoperators and Virtual Environments, (355-385).

Azuma, R.; Baillot, Y.; Behringer, R.; Feiner, S.; Julier, S.; MacIntyre, B. (2001). Recent Advances in Augmented Reality. Computer Graphics and Applications, IEEE, 21, (34-47).

Billinghurst, M.; Kato, H.; Poupyrev, I. (2001). The Magic Book-Moving Seamlessly between Reality and Virtuality. IEEE Computer Graphics and Applications, (1-4).

Billinghurst, M.; Kato, H. (2002). Collaborative augmented reality. Communications of the ACM, 45 (7), (64-70).

Bower, G. H.; Clark, M. C. (1969). Narrative stories as mediators for serial learning. Psychonomic Science.

Bridgeman, B. (1992). A Comparison of Quantitative Questions in Open-Ended and Multiple $\square$ Choice Formats. Journal of Educational Measurement, 29 (3), (253-271).

Bujak, K. R.; Radu, I.; Catrambone, R.; MacIntyre, B.; Zheng, R.; Golubski, G. (2013). A psychological perspective on augmented reality in the mathematics classroom. Computers \& Education.

Cameron, L.; Tanti, M. (2011). Students as learning designers: Using social media to scaffold the experience | eLearning. Catholic University, 27. Faculty of Education, Australian.

Carmigniani, J.; Furht, B.; Anisetti, M.; Ceravolo, P.; Damiani, E.; Ivkovic, M. (2010). Augmented reality technologies, systems and applications. Multimedia Tools and Applications, 51 (1), (341-377).

Cubillo, J.; Martin, S.; Castro, M.; Meier, R. (2012). Control of a remote laboratory by augmented reality. Teaching, Assessment and Learning for Engineering (TALE), 2012 IEEE International Conference on, $W 2 B-11-W 2 B-15$.

Cuendet, S.; Bonnard, Q.; Do-Lenh, S.; Dillenbourg, P. (2013). Designing augmented reality for the classroom. Computers \& Education.

Chen, C.; Tsai, Y. (2012). Interactive augmented reality system for enhancing library instruction in elementary schools. Computers \& Education, 59 (2), (638652).

Dettori, G.; Giannetti, T.; Paiva, A. (2006). Technology-mediated narrative environments for learning. Sense publishers.

Dettori, G.; Paiva, A. (2009). Narrative learning in technology-enhanced environments. In: Anonymous Technology-Enhanced Learning (5569). Springer.

Dickey, M. D. (2006). Ninja Looting for instructional design: the design challenges of creating a game-based learning environment. ACM SIGGRAPH 2006 Educators program (17).

Dieterle, E.; Dede, C. (2006). Building university faculty and student capacity to use wireless handheld devices for learning. Ubiquitous computing in education: Invisible technology, visible impact, (303-328).

Dörner, R.; Geiger, C.; Haller, M.; Paelke, V. (2003). Authoring mixed 
reality-a component and frameworkbased approach. In: Anonymous Entertainment Computing (05-413). Springer.

Doswell, J.; Blake, M.; Butcher-Green, J. (2006). 2006 Fourth IEEE International Workshop on Wireless, Mobile and Ubiquitous Technology in Education (WMTE'06); Mobile Augmented Reality System Architecture for Ubiquitous e-Learning, (121-123).

Ebner, M.; Holzinger, A.; Maurer - Chapter, H. (2007). Universal Access in HumanComputer Interaction. Applications and Services; Web 2.o Technology: Future Interfaces for Technology Enhanced Learning? 4556, (559-568).

Esteban, P.; Restrepo, J.; Trefftz, H.; Jaramillo, J. E.; Alvarez, N. (2006). Augmented Reality for Teaching MultiVariate Calculus. The Fifth IASTED International Conference on web-based education, Puerto Ballarta, México.

Facer, K.; Joiner, R.; Stanton, D.; Reid, J.; Hull, R.; Kirk, D. (2004). Savannah: mobile gaming and learning? Journal of Computer Assisted Learning, 20 (6), (399-409).

Feiner, S.; Macintyre, B.; Seligmann, D. (1993). Knowledge-based augmented reality. Communications of the ACM, 36 (7), (53-62).

Freitas, R.; Campos, P. (2008). SMART: a System of Augmented Reality for Teaching 2nd grade students. 22nd British HCI Group Annual Conference on People and Computers: Culture, Creativity, Interaction-Volume 2 (2730).

Gartner (2012). Technology Research Gartner Inc.

Gibbs, G.; Simpson, C. (2004). Conditions under which assessment supports students' learning. Learning and teaching in higher education, 1 (1), (331).
Goodson, I. F.; Biesta, G.; Tedder, M.; Adair, N. (2010). Narrative learning. Routledge.

Govindasamy, T. (2001). Successful implementation of e-Learning: Pedagogical considerations. The Internet and Higher Education, 4 (3-4), (287299).

Grifantini, K. (2009). Faster Maintenance with Augmented Reality. Technology Review, MIT.

Grimm, P.; Haller, M.; Paelke, V.; Reinhold, S.; Reimann, C.; Zauner, R. (2002). AMIRE-authoring mixed reality. Augmented Reality Toolkit, The First IEEE International Workshop (2).

Hampshire, A.; Seichter, H.; Grasset, R.; Billinghurst, M. (2006). Augmented reality authoring: generic context from programmer to designer. 18th Australia conference on Computer-Human Interaction: Design: Activities, Artefacts and Environments, (409-412).

Hornecker, E.; Dunser, A. (2007). Supporting Early Literacy with Augmented BooksExperiences with an Exploratory Study. German Society of Informatics Annual conference (GI- Jahrestagung).

Hsiao, K.; Rashvand, H. F. (2011). Body Language and Augmented Reality Learning Environment. 2011 Fifth FTRA International Conference on Multimedia and Ubiquitous Engineering. (246-250).

Huang, F.; Zhou, Y.; Yu, Y.; Wang, Z.; Du, S. (2011). Piano AR: A Markerless Augmented Reality Based Piano Teaching System. 2011 Third International Conference on Intelligent HumanMachine Systems and Cybernetics, (47$52)$.

Johnson, L.; Smith, R.; Willis, H.; Levine, A.; Haywood, K. (2011). The 2011 Horizon Report. Austin, Texas: The New Media Consortium.

Johnson, L.; Levine, A.; Smith, R. (2009). Horizon Report 2009. Texas: The New Media Consortium. 
Johnson, L. F.; Levine, A.; Smith, R.; Stone, S. (2010). The Horizon report: 2010 edition. Texas: The New Media Consortium.

Juan, C.; Beatrice, F.; Cano, J. (2008). An Augmented Reality System for Learning the Interior of the Human Body. IEEE Computer Society Eighth IEEE International Conference on Advanced Learning Technologies, (186-189).

Kalawsky, R. S.; Hill, K.; Stedmon, A.W.; Cook, C. A.; Young, A. (2000). Experimental research into human cognitive. Processing in an augmented reality environment for embedded training systems. Virtual Reality, 5 (3), $(9-46)$.

Kamarainen, A. M.; Metcalf, S.; Grotzer, T.; Browne, A.; Mazzuca, D.; Tutwiler, M. S.; Dede, C. (2013). EcoMOBILE: Integrating augmented reality and probe ware with environmental education field trips. Computers \& Education.

Kaufmann, H. (2004). Geometry Education with Augmented Reality. Vienna University of Technology.

Kaufmann, H.; Schmalstieg, D. (2003). Mathematics and geometry education with collaborative augmented reality. Computers \& Graphics, 27 (3), (339345).

Kerawalla, L.; Luckin, R.; Seljeflot, S.; Woolard, A. (2006). Making it real: exploring the potential of augmented reality for teaching primary school science. Virtual Reality, 10 (3-4), (163174).

Klopfer, E.; Perry, J.; Squire, K.; MingFong, J. (2005). Collaborative Learning through Augmented Reality Role Playing. International Society of the Learning Sciences, (311-316).

Klopfer, E.; Squire, K. (2007). Environmental Detectives-the development of an augmented reality platform for environmental simulations Educational
Technology Research and Development, 56 (2), (203-228).

Lampe, M.; Hinske, S. (2007). Integrating interactive learning experiences into augmented toy environments. Pervasive Learning Workshop at the Pervasive Conference, May.

Lang, U.; Wössner, U. (2004). Virtual and Augmented Reality Developments for Engineering Applications. European Congress on Computational Methods in Applied Sciences and Engineering, ECCOMAS 2004, Jyväskylä.

Liarokapis, F.; Anderson, E. (2010). Using Augmented Reality as a Medium to Assist Teaching in Higher Education. Proc of the 31st Annual Conference of the European Association for Computer Graphics (Eurographics 2010), Education Program, Norrkoping, Sweden.

Liarokapis, F.; Mourkoussis, N.; White, M.; Darcy, J.; Sifniotis, M.; Petridis, P. (2004). Web3D and augmented reality to support engineering education. World Transactions on Engineering and Technology Education, 3 (1).

Lin, T.; Duh, H.B.; Li, N.; Wang, H.; Tsai, C. (2013). An investigation of learners' collaborative knowledge construction performances and behavior patterns in an augmented reality simulation system. Computers \& Education, 68, (314 -321).

Luckin, R.; Plowman, L.; Laurillard, D.; Stratfold, M.; Taylor, J.; Corben, S. (2001). Narrative evolution: learning from students' talk about species variation. International Journal of Artificial Intelligence in Education, 12, (100-123).

MacIntyre, B.; Gandy, M.; Dow, S.; Bolter, J. D. (2004). DART: a toolkit for rapid design exploration of augmented reality experiences. 17th annual ACM symposium on User interface software and technology (197-206). 
MacIntyre, B.; Bolter, J.D.; Moreno, E.; Hannigan, B. (2001). Augmented reality as a new media experience. Augmented Reality. IEEE and ACM International Symposium on, (197-206).

Martín, S.; Diaz, G.; Sancristobal, E.; Gil, R.; Castro, M.; Peire, J. (2009). Supporting m-learning: The location challenge. IADIS Mobile Learning Conference.

Martin, S.; Lorenzo, E. J.; Rodriguez-Artacho, M.; Ros, S.; Hernandez, R.; Castro, M. (2012). Ubiquitous anotation and a collaborative open mobile augmented reality. IEEE Global Engineering Education Conference (EDUCON); (1 $-5)$.

Matt Dunleavy, C. D.; Mitchell, R. (2012). Affordances and Limitations of Immersive Participatory. Augmented Reality Simulations for Teaching and Learning, 18 (1), (7-22).

Metaio Augmented Reality Products \& Solutions (2011). Metaio-SDKAugmented Reality 3D.

Miglino, O.; Walker, R. (2010). Teaching to teach with technology-a project to encourage take-up of advanced technology in education. ProcediaSocial and Behavioral Sciences, 2 (2), (2492 -2496).

Milgram, P.; Takemura, H.; Utsumi, A.; Kishino, F. (1994). Augmented Reality: A class of displays on the reality-virtuality continuum. Telemanipulator and Telepresence Technologies, 2351, 11.

Papagiannakis, G.; Singh, G.; MagnenatThalmann, N. (2008). A survey of mobile and wireless technologies for augmented reality systems. Computer Animation and Virtual Worlds, 19 (1), (3-22).

Pemberton, L.; Winter, M. (2009). Collaborative Augmented Reality in Schools. The International Society of the Learning Sciences, 2, (109-111).

Roblyer, M. D.; Edwards, J.; Havriluk, M. A. (2006). Integrating educational technology into teaching. Pearson/ Merrill Prentice Hall.

Rohaya, D.; Rambli, A.; Matcha, W.; Sulaiman, S.; Nayan, M. Y. (2012). Design and Development of an Interactive Augmented Reality Edutainment Storybook for Preschool IERI Procedia, 2, (802 -807).

Santos, I. M.; Ali, N. (2011). Exploring the uses of mobile phones to support informal learning. Education and Information Technologies, 17 (2), (187-203).

Seichter, H.; Looser, J.; Billinghurst, M. (2008). ComposAR: An intuitive tool for authoring AR applications, (177-178).

Shelton, B. E. (2002). Augmented reality and education: Current projects and the potential for classroom learning. New Horizons for Learning, 9 (1).

Shelton, B. E.; Hedley, N. R. (2002). Using augmented reality for teaching EarthSun relationships to undergraduate geography students. Augmented Reality Toolkit, The First IEEE International Workshop, (8).

Stewart Smith, H. (2012). Education with Augmented Reality: AR textbooks released in Japan (video) | ZDNet.

Szalavári, Z.; Schmalstieg, D.; Fuhrmann, A.; Gervautz, M. (1998). Studierstube: An environment for collaboration in augmented reality. Virtual Reality, 3 (1), (37-48).

Van Der Vleuten, C. P. M. (1996). The assessment of professional competence: developments, research and practical implications. Advances in Health Sciences Education, 1 (1), (41-67).

Van't Hooft, M.; Swan, K. (2007). Ubiquitous computing in education: Invisible technology, visible impact. Lawrence Erlbaum Associates, Publishers.

Virvou, M.; Alepis, E. (2005). Mobile educational features in authoring tools for personalised tutoring. Computers \& Education, 44 (1), (53-68). 
Williams, M.; Jones, O.; Fleuriot, C.; Wood, L. (2005). Children and emerging wireless technologies. Proceedings of the SIGCHI conference on Human factors in computing systems-CHI 'O5, (819).

Wojciechowski, R.; Cellary, W. (2013). Evaluation of learners' attitude toward learning in ARIES augmented reality environments. Computers \& Education.

Wu, H.; Lee, S.W.; Chang, H.; Liang, J. (2013). Current status, opportunities and challenges of augmented reality in education. Computers \& Education, 62, (41-49).

Ying, L. (2010). Augmented Reality for remote education. Advanced Computer Theory and Engineering (ICACTE), 2010 3rd International Conference on Advanced Computer Theory and Engineering, 3 (3), (187-191).

\section{PERFIL ACADÉMICO Y PROFESIONAL DE LOS AUTORES}

Joaquín Cubillo Arribas. UNED, Dpto. de Ingeniería Eléctrica, Electrónica y de Control, Escuela Técnica Superior de Ingenieros Industriales, Estudiante de Doctorado y Profesor Titular de Centro Integrado de Formación Profesional.

E-mail: jcubilloarr@educa.jcyl.es

Sergio Martín Gutiérrez. UNED, Dpto. de Ingeniería Eléctrica, Electrónica y de Control, Escuela Técnica Superior de Ingenieros Industriales, Profesor de Universidad.

E-mail: smartin@ieec.uned.es

Manuel Castro Gil. UNED, Dpto. de Ingeniería Eléctrica, Electrónica y de Control, Escuela Técnica Superior de Ingenieros Industriales, Catedrático de Universidad.

E-mail: $\underline{\text { mcastro@ieec.uned.es }}$

Antonio Colmenar Santos. UNED, Dpto. de Ingeniería Eléctrica, Electrónica y de Control, Escuela Técnica Superior de Ingenieros Industriales, Profesor de Universidad.

E-mail: $\underline{\text { acolmenar@ieec.uned.es }}$

\section{DIRECCIÓN POSTAL DE LOS AUTORES}

\section{UNED}

Departamento de Ingeniería Eléctrica, Electrónica y de Control

Escuela Técnica Superior de Ingenieros Industriales C/ Juan del Rosal, 12 28040 MADRID 
Fecha de recepción del artículo: 10/02/14

Fecha de aceptación del artículo: 27/04/14

\section{Como citar este artículo:}

Cubillo Arribas, J.; Martín Gutiérrez, S.; Castro Gil, M.; Colmenar Santos, A. (2014). Recursos digitales autónomos mediante realidad aumentada. RIED. Revista Iberoamericana de Educación a Distancia, volumen 17, $\mathrm{n}^{0}$ 2, pp. 241-274. 